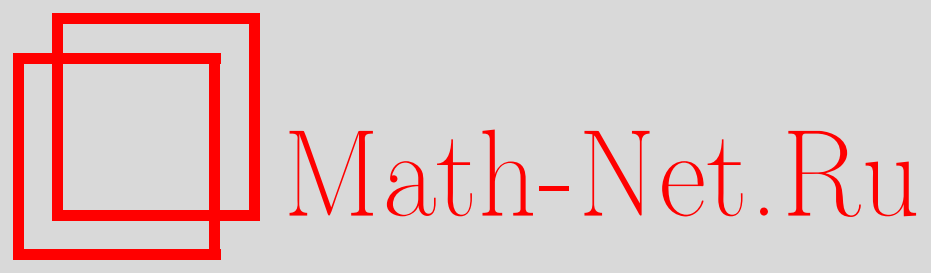

С. Маламанов, Электродинамический водомет, Квант, 2020, номер 6, 30-31

DOI: https://doi.org/10.4213/kvant20200604

Использование Общероссийского математического портала Math-Net.Ru подразумевает, что вы прочитали и согласны с пользовательским соглашением http://www.mathnet.ru/rus/agreement

Параметры загрузки:

IP : 52.6 .47 .48

26 апреля 2023 г., 13:48:56

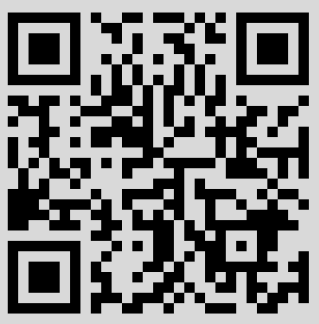




\section{Электродинамический водомет}

\section{С.МАЛАМАНОВ}

\section{... И я пройти еще смогу}

Соленый Тихий океан...

Песня из кинофильма «Я шагаю по Москве»

$\mathrm{B}$ СПОМНИВ ЭТУ ПЕСНЮ, ОДИН СПОсобный ученик подумал: «Погодите, да ведь все океаны и моря соленые. А одно озеро до того соленое, что называется Мертвым морем. Коль так, значит, их вода способна проводить ток! Это же можно както использовать?»

И тут ему вспомнилось, что можно так «организовать» магнитное поле $\vec{B}$ и плотность электрического тока $\vec{j}$, чтобы появилась сила, ускоряющая проводящую жидкость в горизонтальном направлении (рис.1). Это так называемая сила Ампера. Ее плотность (размерность $\mathrm{H} / \mathrm{м}^{3}$ ) равна

$$
\vec{f}=\vec{j} \times \vec{B} .
$$

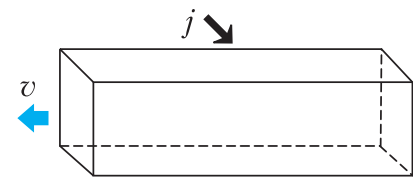

\section{Pис. $1 \quad B$ 仓}

DOI: https://doi.org/10.4213/kvant20200604

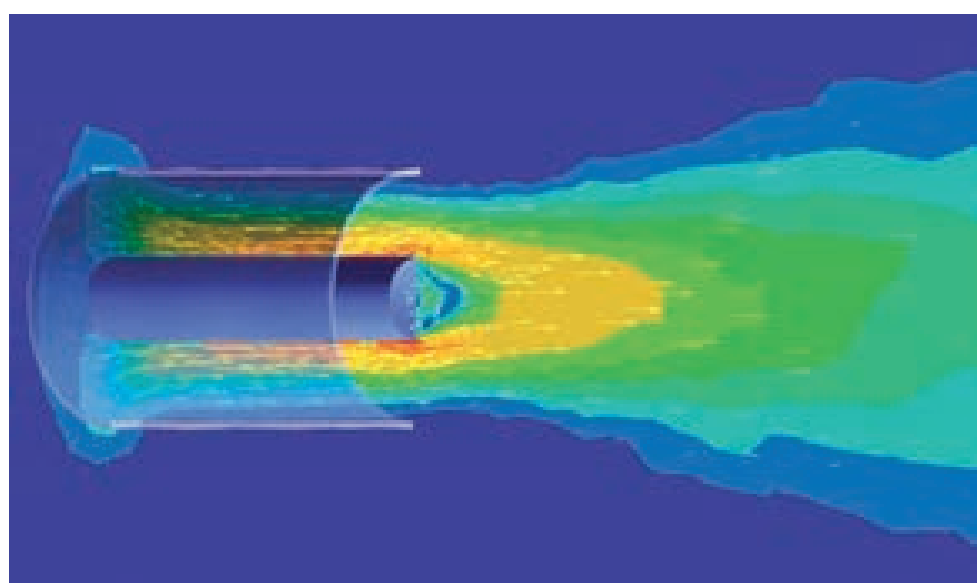

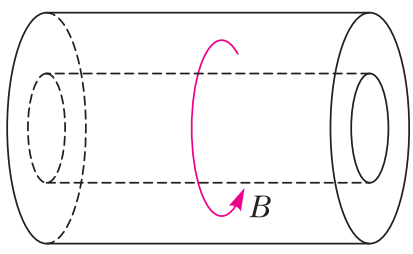

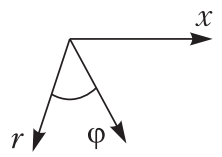

Pnc. 2

Возникающее прямолинейное движение проводящей жидкости в скрещенных электрическом и магнитном полях - один из возможных вариантов. Еще одной простой моделью является течение в ограниченном кольцевом зазоре двух соосных цилиндров, где приложено тороидальное магнитное поле, а между поверхностями поддерживается разность потенциалов, обуславливающая электрический ток. Такую модель иллюстрирует рисунок 2. В этом случае

$$
f_{x}=j_{r} \cdot B_{\varphi} .
$$

Здесь индексы указывают, куда что направлено. Плотность тока связана с напряженностью электрического поля так называемым дифференциальным законом Ома

$$
\vec{j}=\lambda \vec{E},
$$

который в рассматриваемом случае радиального электрического поля принимает вид

$$
j_{r}=\lambda E_{r},
$$

где $\lambda$ - удельная проводимость.

А что будет, если описанное «устройство», в котором разность потенциалов между поверхностями цилиндров поддерживается постоянной и равной $200 \mathrm{~B}$, а в зазоре существует магнитное поле с индукцией 0,1 Тл, поместить в проводящую среду, например - в морскую воду? Теперь уже Способному ученику становится понятно, что появившаяся сила выталкивает жидкость из кольцевого зазора, а получающееся в результате этого течение представляет собой струю. Это хорошо видно на приведенной здесь фотографии. При этом наибольшая скорость, в указанных условиях, оказывается порядка $1 \mathrm{~m} / \mathrm{c}$. 
Это натолкнуло Способного ученика на возможное применение подобного течения движитель, или правильнее сказать в данном случае - водомет. Обрадовавшись такой «находке», он стал обдумывать, как это сделать. И если с электрическим полем все вроде бы понятно, то как получить магнитное поле в кольцевом зазоре? Круговое магнитное поле - как же его организовать?

На ум постоянно приходил виток с током, порождающий осевое магнитное поле (рис.3). И тут он вспомнил, как учитель физики в школе рассказывал о том, что провод линии

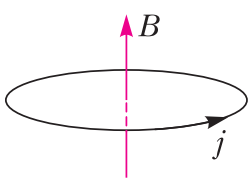

Рис. 3

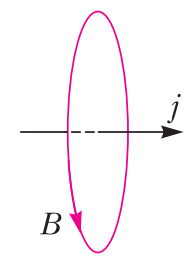

Pис. 4 электропередач окружает круговое магнитное поле. Таким образом, осевой ток способен создать круговое магнитное поле (рис.4). Наши векторы $\vec{j}$ и $\vec{B}$ «просто» поменялись местами. Осталось поместить это магнитное поле в кольцевой зазор.

И опять на помощь пришли уроки физики: надо использовать соленоид. Внутри длинного соленоида, по обмотке которого течет

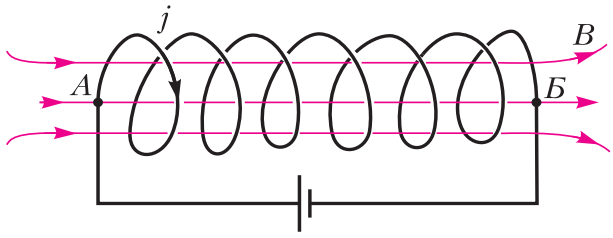

Рис. 5

постоянный электрический ток, возникает однородное магнитное поле (рис.5). Если теперь соединить точки $A$ и $Б$ вместе, то и получится необходимая конфигурация магнитного поля внутри «бублика» (рис.6), который следует «расположить» внутри кольцевого зазора. Правда, надо учесть еще один существенный момент: катушка должна быть «прозрачна» - витки не должны быть намотаны слишком плотно - для протекающей через нее жидкости.

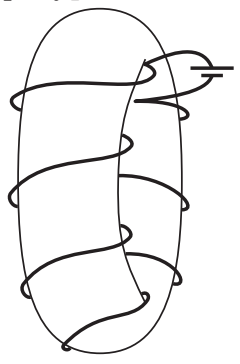

Pис. 6
После этих инженерно-физических решений Способный ученик начал размышлять над тем, где можно применить данный водомет. Так например, его можно использовать для создания импульса, размывающего грунт, для очистки подводных частей корпуса судна, отпугивания морских чудовищ...

\section{МА Т Е МА Т И Ч Е С ИЙ К Р У Ж К}

\section{Как дятел Спятел добывал опилки}

\section{K.KOXACb}

- Кто же мог подумать, что всякие новомодные штучки - все эти бесчисленные пружины, мультизоны, пропитки - оказывается, неглавное, наносное, - извиняющимся голосом говорил дятел Спятел. - Нужно отбросить все это, вернуться, так сказать, к истокам.

DOI: https://doi.org/10.4213/kvant20200605
- Правильно! - согласилась Огрыза. Поэтому я сама изготовлю себе новый матpac! И набью его не какой-нибудь кокосовой шелухой, а обыкновенными опилками!

- Так ведь жестковат матрас-то получится, - возразил дятел Спятел.

- Классическая модель! Жесткий, тяжелый, неуклюжий, но зато на 100\% натуральный! Да что тут рассуждать, я уже сшила чехол для матраса - видишь, какой красивый.

- Красивый. И опилки ты тоже уже купила?

- С опилками загвоздка: их не продают! Продают изделия, а опилки - это отходы. Если бы поблизости была мебельная фабрика, мы бы еще могли что-нибудь сделать... 